\title{
Reactive Oxygen Species in the Signaling and Adaptation of Multicellular Microbial Communities
}

\author{
Michal Čáp, ${ }^{1}$ Libuše Váchová, ${ }^{1,2}$ and Zdena Palková ${ }^{1}$ \\ ${ }^{1}$ Department of Genetics and Microbiology, Faculty of Science, Charles University in Prague, 12844 Prague 2, Czech Republic \\ ${ }^{2}$ Division of Cell and Molecular Microbiology, Institute of Microbiology of the ASCR, v.v.i., 14220 Prague 4, Czech Republic
}

Correspondence should be addressed to Zdena Palková, zdenap@natur.cuni.cz

Received 13 April 2012; Accepted 24 May 2012

Academic Editor: Ivan Spasojevic

Copyright (C) 2012 Michal Čáp et al. This is an open access article distributed under the Creative Commons Attribution License, which permits unrestricted use, distribution, and reproduction in any medium, provided the original work is properly cited.

\begin{abstract}
One of the universal traits of microorganisms is their ability to form multicellular structures, the cells of which differentiate and communicate via various signaling molecules. Reactive oxygen species (ROS), and hydrogen peroxide in particular, have recently become well-established signaling molecules in higher eukaryotes, but still little is known about the regulatory functions of ROS in microbial structures. Here we summarize current knowledge on the possible roles of ROS during the development of colonies and biofilms, representatives of microbial multicellularity. In Saccharomyces cerevisiae colonies, ROS are predicted to participate in regulatory events involved in the induction of ammonia signaling and later on in programmed cell death in the colony center. While the latter process seems to be induced by the total ROS, the former event is likely to be regulated by ROS-homeostasis, possibly $\mathrm{H}_{2} \mathrm{O}_{2}$-homeostasis between the cytosol and mitochondria. In Candida albicans biofilms, the predicted signaling role of ROS is linked with quorum sensing molecule farnesol that significantly affects biofilm formation. In bacterial biofilms, ROS induce genetic variability, promote cell death in specific biofilm regions, and possibly regulate biofilm development. Thus, the number of examples suggesting ROS as signaling molecules and effectors in the development of microbial multicellularity is rapidly increasing.
\end{abstract}

\section{Introduction}

Since the first observations of microorganisms by Antonie van Leeuwenhoek and their isolation and cultivation by Robert Koch, microorganisms have been traditionally viewed as simple unicellular organisms. As a result of this presumption, all microbial studies have been conducted using shaken liquid cultivations. However, during the last few decades, it has become obvious that microorganisms are able to form multicellular structures such as colonies and biofilms. More and more examples of multicellularity have been described, and it has become evident that multicellular behavior, although initially considered an exception, is instead the rule for microbes. Species of the most distant clades of both Archea and Bacteria form biofilms, as did their ancestors some 3.3 billion years ago, indicating that biofilm formation is a universal and ancient bacterial trait [1]. Biofilms and colonies are also formed by eukaryotic microbes (yeasts and molds) in different environments. Multicellular communities are thus prevalent forms of microbial existence in natural settings.

The structural complexity and degree of organization of microbial multicellular structures vary from a simple single-layer biofilm and simple aggregates to complicated structures like the fruiting bodies of myxobacteria and slime molds [2, 3], complex natural biofilms [4] and the colonies of various microbes [5]. Importantly, cells within these structures differentiate and use various signaling molecules to coordinate and regulate the metabolism and development of the community. All these characteristics, that is, structural complexity, cellular differentiation, intercellular signaling and coordinated development, are basic attributes of true multicellularity. However, unlike conventional multicellular organisms, microorganisms retained the ability to survive and divide in their unicellular state.

The biofilm community gains a number of unique properties, especially in terms of resistance to various stresses and toxins. This is of particular importance, because 
the resistance of biofilms to medical treatment is an important problem in current infection control. For this reason, biofilms have become the subject of intensive research in recent years $[1,6-10]$.

The production of reactive oxygen species (ROS) is an inevitable consequence of an aerobic lifestyle. Because of their reactive nature, ROS can cause oxidative damage to DNA, proteins, lipids and other cellular components, and an excess of them leads to extensive cell damage and eventually cell death. To protect themselves from the deleterious effect of ROS, cells have evolved many defensive mechanisms including, for example, enzymes capable of ROS removal, such as catalase, and various peroxidases for the removal of hydrogen peroxide or superoxide dismutase, eliminating superoxide radicals. Although ROS have been traditionally viewed as purely harmful, a more complex picture of their role in cellular physiology has been gradually emerging over the last decade. Recent data have suggested that a certain level of ROS is in fact beneficial to longevity through the adaptive mechanism called hormesis $[11,12]$. During hormesis, low doses of stress or toxin induce mechanisms that protect the organism against this stressor and evoke crossadaptation to other stresses. In addition, a growing number of data suggest that ROS participate in signaling pathways in plants, animals, and fungi [13-15] and even in interspecies communication [16], and it has also been proposed that they play a role in the development of multicellularity [17]. Despite being widely accepted as signaling molecules in higher organisms, little is known about the role of ROS in microbial populations. However, the last few years have produced intriguing new data indicating that ROS-induced processes are involved in differentiation and signaling in yeast and bacterial communities.

Here, we focus on the functions of ROS in multicellular communities of unicellular yeast and bacteria. We summarize current knowledge on the possible roles of ROS and stress defense in the development of S. cerevisiae colonies. In the second part of this review, we summarize current knowledge on the role of oxidative stress defense and endogenous ROS production in other well-studied microbial multicellular structures-Candida albicans and bacterial biofilms.

\section{Saccharomyces cerevisiae Colonies}

The yeast $S$. cerevisiae is one of the most studied model organisms in genetics and molecular biology. It is also widely used for studies on the mechanisms of cellular aging, longevity, stress resistance, and adaptation. However, little is known about yeast life within multicellular communities and only a few groups (including ours) have performed pilot studies that regard development, ageing, adaptation, and differentiation of both laboratory strain colonies (e.g., [1822]; see also below) and biofilm colonies resembling natural biofilms in various aspects (e.g., $[23,24])$.

2.1. Signaling, Stress Defense, and Colony Differentiation. Yeast colonies growing on a complex agar medium with a nonfermentable carbon source undergo several developmental stages characterized by changes in the $\mathrm{pH}$ of the surrounding medium, shifting from acidic to alkali and vice versa [25] (Figure 1). Alkalization of the medium is accompanied by the release of volatile ammonia that can act as a signaling molecule that is able to induce alkalization and ammonia production in neighboring colonies. Thus the development of colonies is synchronized [26]. After several days, the ammonia production declines and colonies enter the second acidic phase. Extensive transcriptional changes occur during the transition from the first acidic to the alkali phase (which occurs between day 7 and 11 of colony development) [27] indicating metabolic reprogramming from a typical respirative metabolism to a different, not yet fully characterized metabolic program. Among others, genes involved in the mitochondrial TCA cycle and oxidative phosphorylation are repressed while other metabolic genes (e.g., peroxisomal $\beta$ oxidation, amino acid metabolic genes, methyl glyoxylate cycle) are induced. Interestingly, in parallel to metabolic reprogramming, the repression of a group of genes that belong to environmental stress response (ESR) genes [28] was observed. These genes also include important players in oxidative stress defense CTT1, SOD1, and CCP1 encoding for cytosolic catalase, cytosolic superoxide dismutase, and mitochondrial cytochrome $\mathrm{c}$ peroxidase, respectively, and a master regulator of ESR genes, MSN4 [27]. Later on during the alkali-to-2nd-acidic-phase transition, some ESR genes, for example, CTT1, are derepressed, while the expression of others such as SOD1 is kept lower than in the 1st acidic phase. Expression changes agreed with the levels of the enzyme activities. Cttlp and Sod1p activities decrease during the alkali phase and increase again after the alkali phase has turned into the second acidic phase $[19,22]$.

In parallel with metabolic reprogramming, the cells of a colony population significantly diversify. Until the beginning of the alkali phase and ammonia production, the colony population is relatively homogeneous. Upon entering the alkali phase, nondividing cells in the colony, which account for the vast majority of the colony population, start to differentiate both in a horizontal and vertical direction. This horizontal diversification leads to the emergence of a cell population of nondividing or slowly dividing chronologically aged cells in the colony center and to the cell population of the colony periphery, where colony accrual occurs and a significant number of cells still divide. Notable physiological differences were found between central and marginal cells in terms of both their metabolism and stress-related features. First, central cells produce levels of ROS several times higher than cells from the colony margin and exhibit some features of programmed cell death, also in contrast to cells from the colony margin $[19,29]$. Secondly, central cells maintain a relatively high activity of oxidative stress defense enzymes Sod1p, Sod $2 \mathrm{p}$, and Ctt1p during the alkali phase, while a significant decrease in these activities was observed in marginal cells [19]. Nevertheless, their increased antioxidant capacity obviously does not protect some of the central cells from high ROS production and cell death. Thirdly, changes in carbon metabolism typical for the acidic-to-alkali transition are mainly induced in the marginal cells [19]. 


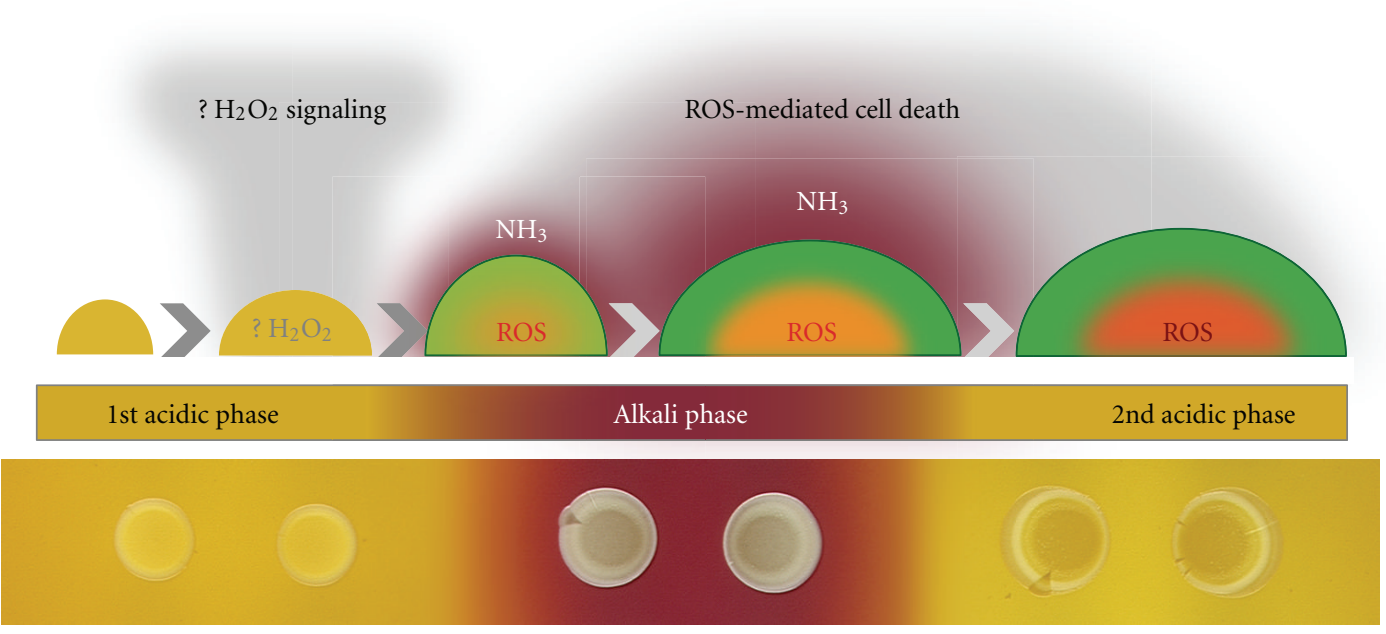

FIGURE 1: Regulatory role of $\mathrm{H}_{2} \mathrm{O}_{2} /$ ROS in the development of yeast colony. Below: development of S. cerevisiae colony, which passes through 1st acidic, alkali and 2nd acidic. Above: periods of hypothesized $\mathrm{H}_{2} \mathrm{O}_{2}$ and ROS involvement in the regulation of colony development. Colonies were photographed with a Hitachi HV-C20 color camera with Cosmicar lenses, Kaiser Prolite illumination system, and NIS Elements software (Laboratory Imaging).

Ammonia signaling seems to be important for this differentiation. A detailed study of sok $2 \Delta$ strain, Sok $2 p$ being a transcription factor involved in various signaling events regulated by the Ras-cAMP-PKA pathway, showed that the center-margin differences described in wild type colonies are diminished or absent in colonies of this ammonia-signalingdeficient strain [30]. Surprisingly, a very similar colony phenotype in terms of differentiation was observed in strains lacking mitochondrial superoxide dismutase Sod2p and cytosolic catalase Cttlp, both of which diminish ammonia signaling [19]. However, the absence of cytosolic superoxide dismutase Sod1p has a different phenotype. Colonies of the $\operatorname{sod} 1 \Delta$ strain produce ammonia at the same time and even in slightly larger quantities than the wild type with colony differentiation even more pronounced than in the wild type [19].

The vertical differentiation observed in the central part of the colony results in two cell layers, the upper and the lower, composed of cells possessing completely different physiologies [18]. Cells on the upper layer are multiple-stress resistant and long-living, while the cells of the lower layer produce more ROS, despite activating the expression of some stress-defense genes, and slowly die.

\subsection{Role of Stress-Defense Mechanisms in Colonies: Direct} Defense or Regulation? Some of the results obtained using colonial populations are in stark contrast to studies on yeast liquid cultivations under starvation conditions, where the indispensability of ESR genes (including those encoding stress defense enzymes) and genes involved in mitochondrial respiration for the long-term survival was shown [3133]. For example, strains deficient in cytosolic superoxide dismutase Sod1p are known to have a severe oxygendependent growth defects, including lysine and methionine auxotrophies as a consequence of oxidative damage to the metabolic pathways synthesizing these amino acids [34]. The deletion of SOD1 also dramatically decreases survival during aging [35]. These defects put selective pressure on the emergence of suppressor mutations compensating for these defects $[36,37]$. On the other hand, the role of mitochondrial Sod2p and Ctt1p in the survival and longevity of liquid yeast populations is less evident. The absence of Sod2p has little effect during fermentative growth but its importance increases when growing on respiratory substrates, consistent with the presumed role of Sod $2 p$ in removing the superoxide radicals resulting from mitochondrial respiration [35]. The role of cytosolic catalase seems ambiguous, since its deletion leads to lower stress protection and a decreased ability to adapt to stress conditions on the one hand $[38,39]$, but also to increased survival during chronological aging on the other [40]. On the whole, antioxidant protection, or at least some of its components, seems to be important for the long-term survival of yeast populations in shaken liquid cultures.

The situation in colonies is almost the opposite. While $\operatorname{sod} 2 \Delta$ and $\operatorname{ctt} 1 \Delta$ colonies are incapable of ammonia signaling, sufficient metabolic reprogramming and differentiation and, consequently, their marginal cell population exhibit decreased survival, sod1s colonies produce ammonia, differentiate and survive in the same manner as wild-type colonies. In addition, sod $1 \Delta$ colonies were almost free of cells with mutations suppressing the stress-sensitivity of $\operatorname{sod} 1 \Delta$ in liquid cultivations. Altogether, $\operatorname{sod} 1 \Delta, \operatorname{sod} 2 \Delta$, and ctt1 $\Delta$ behavior as well as the observed drop in some stressdefense enzyme activities during the alkali phase suggests that it is alkalization, ammonia production, and metabolic reprogramming, not stress defense and direct removal of radicals, that matter in colony differentiation and the survival of part of the population $[19,41]$. In addition, from day 5 onwards, the ROS level in the colony is considerably lower 
than that in liquid cultivations ([19] and unpublished data) in both wild-type colonies and colonies of the $\operatorname{sod} 1 \Delta, \operatorname{sod} 2 \Delta$ and $c t t 1 \Delta$ strains.

Why do sod $1 \Delta$ colonies develop normally with even more pronounced differentiation than wild-type colonies, while the deletion of some other genes involved in antioxidative defense (SOD2, CTT1) is deleterious to the colony's ability to produce ammonia and differentiate? One possibility is that a ROS signaling pathway exists that regulates colony development (Figure 2). This pathway would be activated in wild-type colonies at a particular point in their development and could regulate the beginning of ammonia production (Figure 1). As hypothesized in Figure 2, the signal would be stronger in $\operatorname{sod} 1 \Delta$ colonies, but weaker in $c t t 1 \Delta$ colonies and even weaker or absent in $\operatorname{sod} 2 \Delta$ colonies. The observed phenotypes cannot be simply explained by an increase or decrease in a particular ROS concentration and some more complex mechanism is likely to be involved. Superoxide dismutases catalyze the dismutation of superoxide to hydrogen peroxide and oxygen and so participate in the interconversion of various ROS types. Thus the absence of either of cytosolic or mitochondrial SOD would lead to an increase in superoxide concentration and, simultaneously, to a decrease in $\mathrm{H}_{2} \mathrm{O}_{2}$ concentration in the respective compartment. This leads to alternation in the homeostasis and/or ratio of $\mathrm{H}_{2} \mathrm{O}_{2}$ concentration between the mitochondrial matrix and cytosol. In contrast to superoxide, $\mathrm{H}_{2} \mathrm{O}_{2}$ is relatively stable and can penetrate into other cellular compartments through the membranes. Changes in its production in different compartments thus lead to changes in the $\mathrm{H}_{2} \mathrm{O}_{2}$ gradients and homeostasis and/or $\mathrm{H}_{2} \mathrm{O}_{2}$ concentration ratio between the mitochondrial matrix and cytosol. We propose that this ratio, rather than the absolute concentration of any of the ROS, is the signal that leads to some of the initial changes resulting in ammonia production, alkalization and to the physiological changes connected with it. This model is consistent with the phenotype of $\operatorname{cttl} \Delta$ colonies, since the absence of this enzyme lowers the mitochondrial-tocytosolic $\mathrm{H}_{2} \mathrm{O}_{2}$ ratio, similarly to the sod $2 \Delta$ strain. A possible mode of action of $\mathrm{H}_{2} \mathrm{O}_{2}$ includes the regulation of protein function through peroxiredoxins and thioredoxins, protein modifications by S-glutathiolation and direct inactivation by $\mathrm{H}_{2} \mathrm{O}_{2}[13,42,43]$.

Since it has been shown that different ROS trigger different adaptive responses [44], there clearly must be multiple ROS sensing pathways. That different ROS have different effects was shown in studies of the hormetic effect of superoxide and hydrogen peroxide on liquid cultivations. Both oxidants increase the longevity of the population when applied at moderate concentrations. While superoxide only induces longevity when applied during the logarithmic phase of growth, in contrast $\mathrm{H}_{2} \mathrm{O}_{2}$ only induces longevity when applied to stationary cultures $[40,45]$. This would be consistent with its role in chronologically aging colonies, as proposed above. Moreover, evidence from plant research indicates that the ROS signal is often generated in short pulses [14]. This indicates that not only the amount and type of ROS, but also the precise timing of the ROS signal could be important.
Alternatively, ROS-scavenging enzymes could possess other regulatory functions, possibly independent of their antioxidant properties. For example, the function of the voltage-dependent anion channel (VDAC), a porin of the mitochondrial outer membrane, is diminished in the absence of Sod1p [46]. VDAC plays an important role in regulating mitochondrial activity and apoptosis [47] and its closing leads to a decrease in metabolite exchange and communication between the mitochondrial intermembrane space and the cytosol $[48,49]$. The absence of Sod1p also affects metabolic regulation in cells [50]. Deletion of the SOD1 gene causes a lessening of glucose repression, an important regulatory mechanism affecting nearly all aspects of S. cerevisiae metabolism. Moreover, sod1 $\Delta$ cells have an increased level of mitochondrial biomass when growing in both media, with a repressing or nonrepressing carbon source. Both superoxide dismutases, Sod1p and Sod2p, were identified in a large-scale protein-protein interaction study as potential regulators of DNA repair and chromatin remodeling [51].

\subsection{ROS in Programmed Cell Death in Colony. Beside their} possible role in signaling leading to ammonia production and the start of colony differentiation, ROS seem to play an important role in the further development of differentiated cells (Figure 1). Programmed cell death in yeast can be induced by various signals, but their common factor is an increased ROS concentration (for reviews on yeast apoptosis, see [52-55]). ROS therefore seem to be the executioners of programmed cell death in yeast. As described above, cells in the center of a differentiated colony undergo programmed cell death, while cells at the colony margin are healthy and free of ROS $[19,29]$. In contrast, the decreased center-margin differentiation observed in the colonies of non-ammoniaproducing strains results in an increased cell death rate at the colony margin $[19,29]$. A relatively high production of ROS occurs in the center of differentiated ammoniaproducing wild-type and $\operatorname{sod} 1 \Delta$ colonies. Notably, oxidativestress-defense-deficient mutants with a defect in ammonia production ( $\operatorname{sod} 2 \Delta$ and $c t t 1 \Delta$ ) do not exhibit increased ROS production in the colony center [19]. We propose that ROS are produced by the central cells in response to ammonia and/or alkalization and their production leads to cell death. ROS production in these cells is probably not a consequence of a low antioxidant capacity of the central cells, but rather part of a developmental program of the colony.

The dead cells in the colony center are likely to release nutrients that are then used by the cells at the edge of the colony to grow and survive $[29,56]$. In addition, dead cells not only release nutrients from their biomass, but also stop consuming from the common nutrient pool. Since cells in the margin of the colony are younger and have better prospects of colonizing other localities, it makes sense if the colony invests in these prosperous cells at the expense of central cells. Opponents of the concept of programmed cell death in microorganisms could argue that cell death could bring no advantage for a unicellular organism, since the whole organism (one cell) dies and so this trait could 

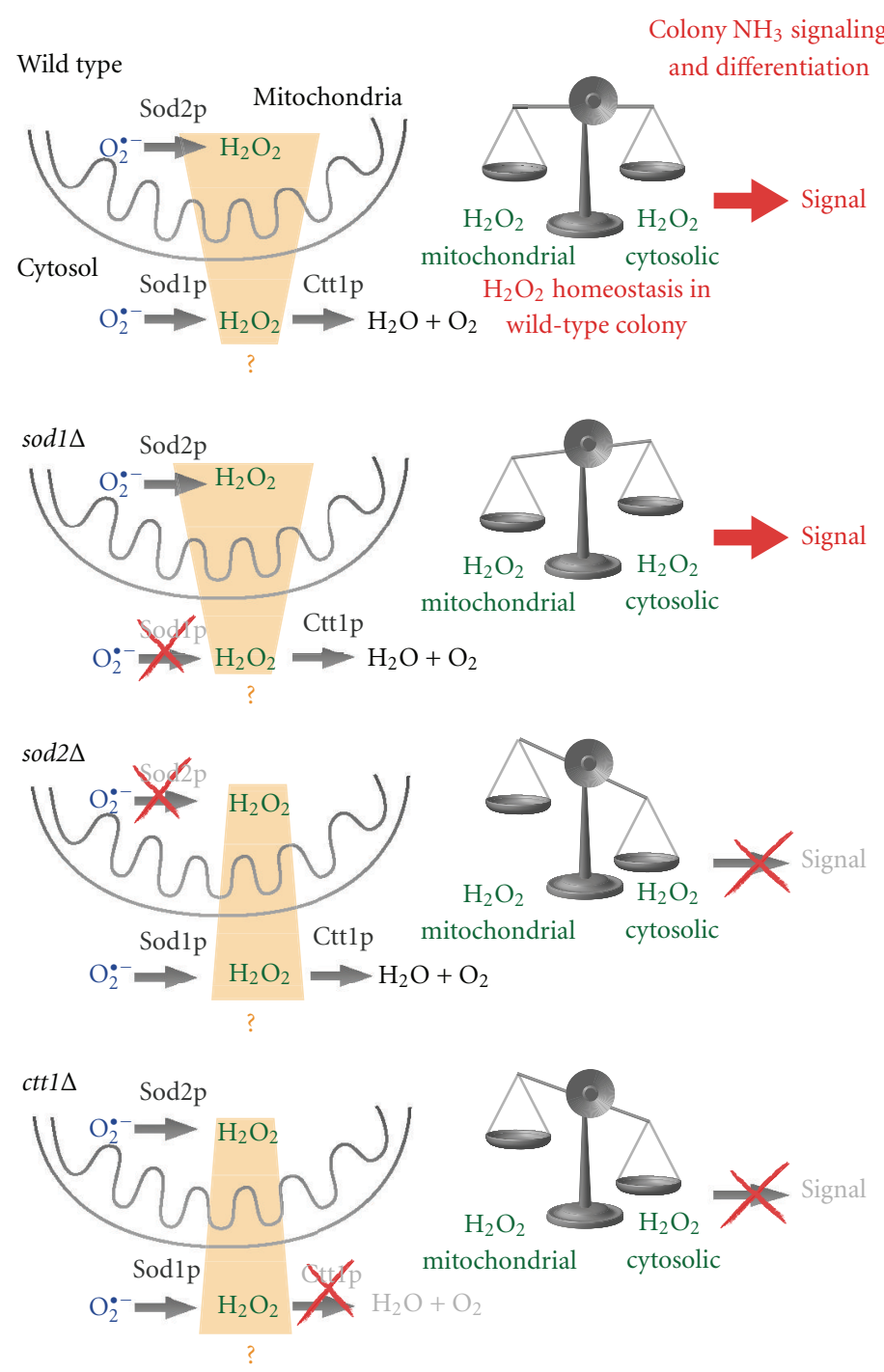

FIGURE 2: Hypothesis on the effect of $\mathrm{H}_{2} \mathrm{O}_{2}$ balance on induction of ammonia signaling. Left: predictions of changes in $\mathrm{H}_{2} \mathrm{O}_{2}$ concentration in cytosol and mitochondria of wild type and three oxidative-stress-defense-deficient strains based on reactions catalyzed by three main stress defense enzymes, cytosolic and mitochondrial superoxide dismutase Sod1p and Sod2p, respectively, and cytosolic catalase Ctt1p. Orange arrows indicate predicted $\mathrm{H}_{2} \mathrm{O}_{2}$ gradient between mitochondria and cytosol in wild-type strain and the three mutants. $\mathrm{H}_{2} \mathrm{O}_{2}$ gradient in wild-type cells is proposed on the basis of the prediction that mitochondria are the major site of ROS production in starving respiring cells from acidic-phase colonies. Right: the balances compare the mitochondrial-cytosolic $\mathrm{H}_{2} \mathrm{O}_{2}$-homeostasis of the particular mutant strain and the wild-type colony. The $\mathrm{H}_{2} \mathrm{O}_{2}$ imbalance towards the higher $\mathrm{H}_{2} \mathrm{O}_{2}$ concentration in the cytosol abolishes the induction of ammonia signaling and proper colony development and differentiation.

not be a subject to natural selection. However, when we consider unicellular organisms in terms of populations, it makes sense that the death of some cells could increase the prospects for survival of other cells in the same population. Moreover, microbial communities are often of clonal origin in nature; that is, they originate from one or a few cells and thus it is highly probable that the nutrients released by the sacrificed cells would benefit the kin of these cells, making this programmed cell death evolutionarily sustainable.

\section{Candida Biofilms}

Biofilms formed by Candida sp. can be serious problems in medical treatment, as they are usually highly resistant to extracellular toxins and drugs. ROS presumably play some role in Candida biofilms. Transcriptomic studies revealed that the biofilm population increases the expression of stressdefense genes, in particular those involved in combating oxidative stress, when compared to planktonic cultures [57]. 
Similar results were confirmed at the proteomic level [58]. The ROS level is dramatically decreased in biofilm when compared to a planktonic cultivation [58]. Whether this is a consequence of the activation of antioxidant mechanisms in biofilms or whether life in the biofilm per se results in a decreased ROS production (as with life in a colony) is unclear. It seems that a common mechanism for oxidative stress resistance and multicellular behavior exists in C. albicans, since cell adhesion, biofilm formation, and oxidative stress resistance are influenced by a common factor, the cell wall protein Hwp2p [59]. As the release of ROS during phagocyte respiratory burst is a crucial part of the immune response, adaptation to oxidative stress and oxidative stress defense enzymes help the yeast cells to survive respiratory burst and are thus important factors in pathogen virulence [60]. The increased oxidative stress defense of biofilms could also be responsible for their increased resistance to antifungal agents such as azoles, the toxicity of which involves the production of ROS [61].

3.1. Farnesol Signaling and ROS. Intercellular signaling by farnesol is involved in the induction of oxidative stress defense. Farnesol is a sesquiterpene alcohol produced by Candida sp. that acts as a quorum sensing (QS) molecule [62]. Quorum sensing is a synchronized transcriptional response of a microbial population to the presence of a small molecule called an autoinducer. Given that the autoinducer is produced continuously by all cells in the population, its concentration is proportional to the cell density.

Farnesol in C. albicans was shown to inhibit hyphae formation [63], to inhibit biofilm growth [64], to induce programmed cell death [65], to evoke ROS production [66], and to promote resistance to oxidative stress [67]. The latter involves farnesol-induced catalase expression via inhibition of the Ras-cAMP pathway [66] and, in parallel, farnesol-induced ROS production, which adapts cells to oxidative stress and induces protective mechanisms [68]. Farnesol thus acts as an intercellular adaptive signal that confers oxidative stress resistance to the cells within the same population. It is possible that the farnesol-induced high level of ROS and membrane-permeable hydrogen peroxide, in particular, participate in the farnesol signaling pathway, thus behaving as another intercellular signaling molecule. The possible signaling role of $\mathrm{H}_{2} \mathrm{O}_{2}$ in C. albicans is illustrated by the findings that low concentrations of hydrogen peroxide can induce the yeast-to-hyphal morphological transition [69], while higher concentrations induce programmed cell death $[70,71]$. It was shown that $\mathrm{H}_{2} \mathrm{O}_{2}$ activates the AP-1-like stress-responsive transcription factor Caplp, the stress-activated protein kinase Hoglp and also the checkpoint kinase Rad53p, which regulates hyperpolarized bud growth and filamentation [72-74]. Interestingly, these $\mathrm{H}_{2} \mathrm{O}_{2}$-regulated pathways are regulated and coordinated by the antioxidant enzyme thioredoxin, which appears to be a master regulator of redox signaling in C. albicans [72].

Farnesol also induces ROS production in other fungal and bacterial species [75-77]. Farnesol can thus act like an antibiotic, killing competing microbes and, in parallel, it induces mechanisms (e.g., cAMP-mediated oxidative stress adaptation) that protect the producing cells from farnesol's toxic effect. A similar strategy was described in killer toxins produced by different yeast species [78]. Different outcomes described for farnesol signaling (i.e., adaptation, differentiation or apoptotic cell death) could be the consequences of various concentrations of farnesol and combination of the farnesol signal with other factors, for example, other signaling molecules, cell physiology, nutrient status, and cell location in the biofilm.

\section{Bacterial Biofilms}

The stages of biofilm formation, that is, attachment, maturation, and dispersal of the bacterial biofilm, are all regulated by environmental cues as well as by intercellular signaling molecules $[6,79]$. The role of various QS signals, indole, and polyamine signaling in the regulation of biofilm development has been described [80-82]. Beside these signaling molecules, ROS are another possible signal involved in biofilm formation (Figure 3). The role of ROS in cell death and the generation of genetic variants within a biofilm is well-described, while ROS' signaling function and crosstalk with other signaling pathways as well as their role in microbe-microbe, host-pathogen, or host-symbiont types of interactions are slowly emerging but mostly remain to be discovered.

4.1. ROS-Induced Diversity and Differentiation of Cells within a Biofilm. Many bacterial species develop genetic variability when growing within a biofilm, but not during cultivations of planktonic cells [83-86]. Variability was demonstrated as the frequency of the different colony morphotypes, resistance to antibiotics, swimming and sliding motility and exopolysaccharide production. Since different environmental conditions require different cell adaptations, genetic variability increases the chances of the community surviving under a broader spectrum of conditions. In the biofilms of Pseudomonas aeruginosa, the emergence of their genetic variability is dependent on oxidative-stress-induced DNA double-strand breaks and on their repair by the RecA system, which introduces genome rearrangements [84]. Interestingly, increasing resistance to oxidative stress or adding an antioxidant to the medium significantly reduced cell variance in the biofilm, while deletion of the catalase gene increased the variance [84]. ROS- and RecA-dependent biofilm cell variation was also described in Listeria monocytogenes [87]. Similar results were obtained from studies of Staphylococcus pneumoniae biofilm phenotypic variation. In this case, the "suicide" gene $s p x B$ encodes for pyruvate oxidase, which produces high amounts of hydrogen peroxide and which is responsible for the unusually high death rate in $S$. pneumoniae stationary cultures and possibly also in biofilms [88]. Likewise, SpxB-mediated production of $\mathrm{H}_{2} \mathrm{O}_{2}$ induces the cell death of about $10 \%$ of the population, leading to the release of DNA from the cells in two oral bacterial species, Streptococcus sanguinis and Streptococcus gordonii $[89,90]$. This extracellular DNA (eDNA) 
is an important part of the biofilm extracellular matrix, it enhances cell-cell adhesion, regulates biofilm dispersal, serves as a nutrient source, and is available to be taken up and incorporated into the chromosome by competent cells [91-95]. Given that streptococcal biofilms contain a high percentage of competent cells [96], eDNA release could be an important factor in creating genetic variability in biofilms. Moreover, the mutagenic activity of $\mathrm{H}_{2} \mathrm{O}_{2}$ [97] towards eDNA even increases this variability. Interestingly, $s p \times B$ expression is controlled by the catabolic repression regulator CcpA, linking the roles of metabolism and $\mathrm{H}_{2} \mathrm{O}_{2}$ in biofilm development [98]. Hydrogen-peroxide-induced genetic variation and cell death were also reported in biofilms of Pseudoalteromonas tunicata, Marinomonas mediterranea, Caulobacter crescentus, and Chromobacterium violaceum, depending on the presence of the lysine oxidase encoded by the alpP gene and its homologues [99]. This hydrogen peroxide-producing enzyme is common among bacterial species, which makes variability and cell death regulated by ROS a common bacterial trait. Interestingly, AlpP-mediated cell death is also important for dispersal of the biofilm, that is, the release of planktonic cells from the biofilm. Cell death in the biofilm center presumably provides nutrients that increase the size, metabolic activity, and phenotypic variability of the dispersed cells [100]. Remarkably, besides $\mathrm{H}_{2} \mathrm{O}_{2}$, lysine oxidase also produces ammonia, but its possible signaling function in biofilms has not been explored. $P$. aeruginosa biofilm dispersal and cell differentiation are also regulated by the signaling molecule nitric oxide, a radical that could give rise to a spectrum of oxidants called reactive nitrogen species (RNS). Low concentrations of NO caused $P$. aeruginosa biofilm dispersal and enhanced swimming and swarming cell motilities, while higher NO concentrations induced cell death [101]. At least some of these effects are probably induced by NO-derived RNS, as RNS were detected in the biofilm. NO is produced by $P$. aeruginosa cells under anaerobic conditions through anaerobic respiration from nitrates and nitrites and is further reduced by NO reductase. Since the interior of a $P$. aeruginosa biofilm is a hypoxic environment [102, 103], the level of anaerobic NO and RNS production should be proportional to biofilm depth. In this way, cell position within the biofilm could be sensed and dispersal and cell death could be coregulated with biofilm growth [101].

Endogenous ROS production in the biofilm is the source of the high variability of biofilm cells, and ROS could act as a signal that mediates the cell death of a sensitive subpopulation in the deeper layers of the biofilm and metabolic differentiation in the upper part of the biofilm. The bacterial biofilm communities thus strikingly resemble metabolic differentiation and ammonia-regulated cell death in S. cerevisiae colonies described above. Whether ROSmediated cell death is part of programmed colony/biofilm development or it is simply the inability of a sensitive subpopulation to withstand the accumulation of toxic byproducts of metabolism remains an unanswered question. The findings from yeast colonies and bacterial biofilms showing that cell death in one subpopulation leads to metabolic activity and variability in the other subpopulation,

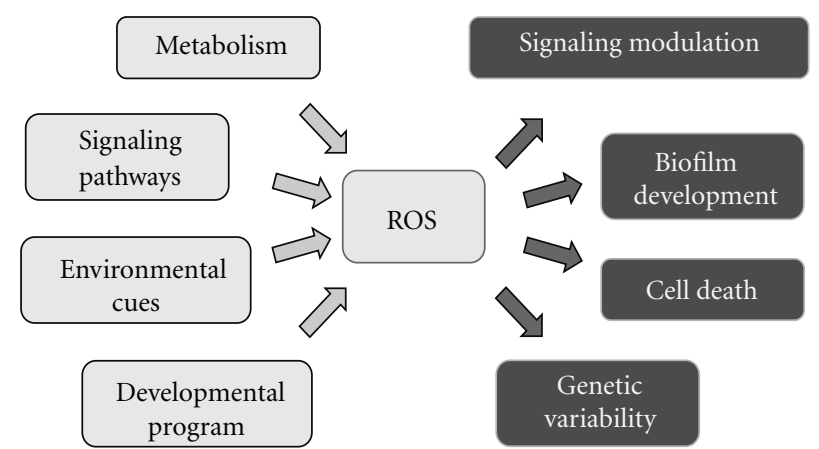

FIGURE 3: Inputs and outputs of ROS production in biofilms. Left: summary of processes inducing ROS production. Right: processes affected by ROS.

and thus increase fitness of the population as a whole, argue for the former option.

4.2. ROS-Dependent Signaling in Biofilm. Biofilm development is probably governed by both environmental cues as well as by intercellular signaling molecules. The best-studied intercellular signal is QS, which also plays a role in biofilm formation and development $[6,79]$. A variety of autoinducer molecules have been identified in bacteria, of which the most studied are the species-specific acylated homoserine lactones (AHLs) found in many Gram-negative bacteria and the furanosyl borate ester AI-2 produced and recognized by both Gram-positive and Gram-negative species. It has been proposed that many autoinducers are able to induce ROS production, making ROS possible downstream signals or effectors of QS pathways [104]. QS plays an important role in the processes of biofilm formation and dispersal. For example, QS signaling through AI-2 in Vibrio cholerae, Listeria monocytogenes, Bacillus cereus, and Staphylococcus epidermidiss and the autoinducer protein AIP in Staphylococcus aureus inhibit biofilm formation. In contrast, a positive effect on biofilm formation was described for AI-2 signaling in Bacillus subtilis, Lactobacillus rhamnosus as well as in AHLmediated QS in $P$. aeruginosa $[79,105]$. Interestingly, ROS seem to be able to modulate quorum sensing in various ways. ROS can inhibit autoinducer peptide signaling in $S$. aureus in vitro [106]. In a study of the mouse skin infection model, ROS-producing enzymes of the immune system were indispensable for defense against infection by the wildtype $S$. aureus strain, but not necessary for defense against a QS-deficient strain, indicating that QS molecules could be a target for oxidation by the immune system in vivo [106]. Superoxide also decreases the expression of QS locus comQXP in B. subtilis [107]. On the other hand, ROS have the potential to increase the QS signal, as certain derivates of AHL oxidation by ROS exhibit increased biological activity [108]. In addition, QS regulates the expression of oxidative stress defense genes in various bacterial species [109-112].

Additional indications of ROS-dependent signaling pathways regulating biofilm growth have recently appeared. Enterococcus faecalis biofilm formation is dependent on the presence of the $x d h$ gene, presumably encoding for a 
selenoprotein xanthine dehydrogenase involved in purine metabolism and uric acid utilization and possibly evoking ROS production [113]. Cells in an E. faecalis biofilm produce high levels of ROS via a mechanism that is reliant on the presence of xanthine dehydrogenase, its cofactors selenium and molybdenum and its substrate uric acid. An intriguing model was proposed, in which uric acid in the environment is metabolized by E. faecalis cells with concomitant $\mathrm{H}_{2} \mathrm{O}_{2}$ production, which in turn induces biofilm formation. $\mathrm{H}_{2} \mathrm{O}_{2}$ thus would be a metabolic byproduct with a signaling function. Since uric acid is abundant in blood and urine, that is, preferred environments for E. faecalis, it makes sense that detecting this metabolite triggers the formation of the biofilm to successfully colonize the host [113].

In multispecies oral biofilms, streptococci produce $\mathrm{H}_{2} \mathrm{O}_{2}$ from pyruvate as a mean of biochemical warfare against other species, as well as a regulator of its own development as described above. However, the oral pathogen Aggregatibacter actinomycetemcomitans uses this streptococci-produced $\mathrm{H}_{2} \mathrm{O}_{2}$ as a signal that activates the expression of the compliment resistance protein ApiA, which helps A. actinomycetemcomitans to resist the host's nonspecific immune response [114].

Some results suggest that ROS play a role in modulating the indole signaling pathway. Indole acts as an intercellular signal in many bacterial species [80]. Similarly to other signaling molecules, indole even induces a response in some species that do not synthesize it, and thus acts as an interspecies signaling molecule. In Escherichia coli, indole, which is synthetized by the enzymes coded by the tnaAL operon, inhibits biofilm growth regulates pathogenicity and the expression of multidrug resistance genes $[115,116]$. Among other signals, tnaA expression is induced by ROS and repressed by growth in a biofilm [117, 118]. Indole was proposed to act as an oxidant in membranes and to induce membrane rearrangements [119]. Furthermore, some antibiotics induce indole production, which consequently inhibits biofilm formation in E. coli, via a mechanism involving hydrogen peroxide [120], showing that indole signaling and $\mathrm{H}_{2} \mathrm{O}_{2}$ cooperate in a pathway inhibiting biofilm growth. The opposite results, that is, indole-induced biofilm formation in E. coli and other species, were reported by others [121].

4.3. Biofilms and Oxidative Stress Adaptation. As with $C$. albicans biofilms and $S$. cerevisiae colonies, there is obviously a connection between the life of bacteria within a multicellular structure (biofilm) and their adaptation to oxidative stress. A number of genes have been identified that are important for both biofilm growth and oxidative stress resistance. Examples are the transcriptional repressor Rex and trigger factor RpoS in Streptococcus mutans [122, 123], in-silico-identified genes uspE and gadX in E. coli [124], posttranslational regulator CsrA in Campylobacter jejuni [125] and two-component systems GacS-GacA in Pseudomonas sp. and ColR-ColS in Xanthomonas citri [126, 127]. The redox-sensitive DNA-binding protein OxyR is a well-studied transcription regulator that mediates oxidative stress response in many Gram-negative bacteria [128]. OxyR is activated by forming an intramolecular disulfide bond upon reaction with $\mathrm{H}_{2} \mathrm{O}_{2}$, which leads to the expression of OxyR-regulated genes. The role of OxyR in biofilm formation has been described in several bacterial species. In E. coli, OxyR induces biofilm formation by activating expression of the surface adhesin Ag43, which is responsible for cell-to-cell attachment and surface adherence [129]. Similarly, OxyR regulates cell attachment by increasing the expression of adherent fimbriae in Serratia marcescens and Klebsiella pneumoniae [130,131] and OxyR's function in biofilm formation was also reported in Neisseria gonorrhoeae and Tannerella forsythia $[132,133]$.

\section{Conclusions}

Both endogenous and exogenous reactive oxygen species are important stress factors in the life of microorganisms. Endogenous ROS production is an inevitable consequence of microbial life in the presence of oxygen and can be even potentiated by some antibiotics that induce ROS production in sensitive microbes [134-136]. Exogenous ROS can be encountered during immune response to the presence of microbes inside the animal or plant body. In addition, many bacterial species release ROS as an oxidative weapon against competitors in multispecies populations. In these cases, ROS are produced by specialized enzymes. ROS are thus widely used as a means of biochemical warfare in nature. In order to defend against the deleterious effects of ROS, microorganisms have evolved efficient mechanisms of ROS removal. On the other hand, various pieces of data suggest that ROS could play an active and important role in processes like growth autoinhibition, cell death, and biofilm/colony development in both yeast and bacteria. In such cases, the enzymes producing ROS are tightly regulated as part of a biofilm developmental program and ROS are the effectors of some intrinsic regulation. Finally, ROS can act as signaling molecules either by targeting specific signaling pathways (e.g., kinases or transcription factors) or by, for example, modifying other signaling molecules such as quorum sensing factors. The large number of ROSproducing enzymes and the many different responses to ROS suggest that ROS-mediated processes are universal in the microbial world. Improving our understanding of the regulation and signaling driven by ROS could thus provide deeper insight into complex biological processes including the formation of biofilms, multicellular structures with important implications in medicine and other fields. The possibility of interfering with the signaling involved in biofilm formation or biofilm dispersal with ROS-producing or ROS-scavenging agents is especially attractive.

\section{Acknowledgments}

This work was supported by the Grant Agency of the Czech Republic (204/08/0718), the Ministry of Education (MSM0021620858), Charles University in Prague (SVV2012-265202 and UNCE 2040130), and RVO 61388971. 


\section{References}

[1] L. Hall-Stoodley, J. W. Costerton, and P. Stoodley, "Bacterial biofilms: from the natural environment to infectious diseases," Nature Reviews Microbiology, vol. 2, no. 2, pp. 95-108, 2004.

[2] S. J. Annesley and P. R. Fisher, "Dictyostelium discoideum-a model for many reasons," Molecular and Cellular Biochemistry, vol. 329, no. 1-2, pp. 73-91, 2009.

[3] G. J. Velicer and M. Vos, "Sociobiology of the myxobacteria," Annual Review of Microbiology, vol. 63, pp. 599-623, 2009.

[4] S. Elias and E. Banin, "Multi-species biofilms: living with friendly neighbors ," FEMS Microbiology Reviews. In press.

[5] Z. Palková and L. Váchová, "Life within a community: benefit to yeast long-term survival," FEMS Microbiology Reviews, vol. 30, no. 5, pp. 806-824, 2006.

[6] D. López, H. Vlamakis, and R. Kolter, "Biofilms," Cold Spring Harbor Perspectives in Biology, vol. 2, no. 7, Article ID a000398, 2010.

[7] G. G. Anderson and G. A. O’Toole, "Innate and induced resistance mechanisms of bacterial biofilms," Current Topics in Microbiology and Immunology, vol. 322, pp. 85-105, 2008.

[8] L. Hall-Stoodley and P. Stoodley, "Evolving concepts in biofilm infections," Cellular Microbiology, vol. 11, no. 7, pp. 1034-1043, 2009.

[9] N. Høiby, T. Bjarnsholt, M. Givskov, S. Molin, and O. Ciofu, "Antibiotic resistance of bacterial biofilms," International Journal of Antimicrobial Agents, vol. 35, no. 4, pp. 322-332, 2010.

[10] K. Lewis, "Multidrug tolerance of biofilms and persister cells," Current Topics in Microbiology and Immunology, vol. 322, pp. 107-131, 2008.

[11] Y. Pan, "Mitochondria, reactive oxygen species, and chronological aging: a message from yeast," Experimental Gerontology, vol. 46, no. 11, pp. 847-852, 2011.

[12] M. Ristow and S. Schmeisser, "Extending life span by increasing oxidative stress," Free Radical Biology and Medicine, vol. 51, no. 2, pp. 327-336, 2011.

[13] T. Finkel, "Signal transduction by reactive oxygen species," Journal of Cell Biology, vol. 194, no. 1, pp. 7-15, 2011.

[14] R. Mittler, S. Vanderauwera, N. Suzuki et al., "ROS signaling: the new wave?" Trends in Plant Science, vol. 16, no. 6, pp. 300$309,2011$.

[15] B. Scott and C. J. Eaton, "Role of reactive oxygen species in fungal cellular differentiations," Current Opinion in Microbiology, vol. 11, no. 6, pp. 488-493, 2008.

[16] M. A. Torres, "ROS in biotic interactions," Physiologia Plantarum, vol. 138, no. 4, pp. 414-429, 2010.

[17] H. Lalucque and P. Silar, "NADPH oxidase: an enzyme for multicellularity?" Trends in Microbiology, vol. 11, no. 1, pp. 9-12, 2003.

[18] M. Cap, L. Stepanek, K. Harant, L. Vachova, and Z. Palkova, "Cell differentiation within a yeast colony: metabolic and regulatory parallels with a tumor-affected organism," Molecular Cell, vol. 46, no. 4, pp. 436-448, 2012.

[19] M. Čáp, L. Váchová, and Z. Palková, "Yeast colony survival depends on metabolic adaptation and cell differentiation rather than on stress defense," Journal of Biological Chemistry, vol. 284, no. 47, pp. 32572-32581, 2009.

[20] S. Piccirillo, M. G. White, J. C. Murphy, D. J. Law, and S. M. Honigberg, "The Rim101p/PacC pathway and alkaline $\mathrm{pH}$ regulate pattern formation in yeast colonies," Genetics, vol. 184, no. 3, pp. 707-716, 2010.
[21] L. Váchová, O. Chernyavskiy, D. Strachotová et al., "Architecture of developing multicellular yeast colony: spatiotemporal expression of Atolp ammonium exporter," Environmental Microbiology, vol. 11, no. 7, pp. 1866-1877, 2009.

[22] L. Váchová, H. Kučerová, F. Devaux, M. Úlehlová, and Z. Palková, "Metabolic diversification of cells during the development of yeast colonies," Environmental Microbiology, vol. 11, no. 2, pp. 494-504, 2009.

[23] V. Št'ovíček, L. Váchová, M. Kuthan, and Z. Palková, "General factors important for the formation of structured biofilm-like yeast colonies," Fungal Genetics and Biology, vol. 47, no. 12, pp. 1012-1022, 2010.

[24] L. Váchová, V. Štoví, O. Hlaváček et al., "Flo11p, drug efflux pumps, and the extracellular matrix cooperate to form biofilm yeast colonies," Journal of Cell Biology, vol. 194, no. 5, pp. 679-687, 2011.

[25] Z. Palkova, B. Janderova, J. Gabriel, B. Zikanova, M. Pospisek, and J. Forstova, "Ammonia mediates communication between yeast colonies," Nature, vol. 390, no. 6659, pp. 532-536, 1997.

[26] Z. Palková and J. Forstová, "Yeast colonies synchronise their growth and development," Journal of Cell Science, vol. 113, no. 11, pp. 1923-1928, 2000.

[27] Z. Palková, F. Devaux, M. Řičicová, L. Mináriková, S. Le Crom, and C. Jacq, "Ammonia pulses and metabolic oscillations guide yeast colony development," Molecular Biology of the Cell, vol. 13, no. 11, pp. 3901-3914, 2002.

[28] A. P. Gasch and M. Werner-Washburne, "The genomics of yeast responses to environmental stress and starvation," Functional and Integrative Genomics, vol. 2, no. 4-5, pp. 181192, 2002.

[29] L. Váchová and Z. Palková, "Physiological regulation of yeast cell death in multicellular colonies is triggered by ammonia," Journal of Cell Biology, vol. 169, no. 5, pp. 711-717, 2005.

[30] L. Váchová, F. Devaux, H. Kučerová, M. Řičicová, C. Jacq, and Z. Palková, "Sok2p transcription factor is involved in adaptive program relevant for long term survival of Saccharomyces cerevisiae colonies," Journal of Biological Chemistry, vol. 279, no. 36, pp. 37973-37981, 2004.

[31] D. Gresham, V. M. Boer, A. Caudy et al., "System-level analysis of genes and functions affecting survival during nutrient starvation in Saccharomyces cerevisiae," Genetics, vol. 187, no. 1, pp. 299-317, 2011.

[32] A. A. Petti, C. A. Crutchfield, J. D. Rabinowitz, and D. Botstein, "Survival of starving yeast is correlated with oxidative stress response and nonrespiratory mitochondrial function," Proceedings of the National Academy of Sciences of the United States of America, vol. 108, no. 45, pp. E1089E1098, 2011.

[33] J. Wu, N. Zhang, A. Hayes, K. Panoutsopoulo, and S. G. Oliver, "Global analysis of nutrient control of gene expression in Saccharomyces cerevisiae during growth and starvation," Proceedings of the National Academy of Sciences of the United States of America, vol. 101, no. 9, pp. 3148-3153, 2004.

[34] X. F. Liu, I. Elashvili, E. B. Gralla, J. S. Valentine, P. Lapinskas, and V. C. Culotta, "Yeast lacking superoxide dismutase. Isolation of genetic suppressors," Journal of Biological Chemistry, vol. 267, no. 26, pp. 18298-18302, 1992.

[35] V. D. Longo, E. B. Gralla, and J. S. Valentine, "Superoxide dismutase activity is essential for stationary phase survival in Saccharomyces cerevisiae: mitochondrial production of toxic oxygen species in vivo," Journal of Biological Chemistry, vol. 271, no. 21, pp. 12275-12280, 1996. 
[36] L. T. Jensen, R. J. Sanchez, C. Srinivasan, J. S. Valentine, and V. C. Culotta, "Mutations in Saccharomyces cerevisiae ironsulfur cluster assembly genes and oxidative stress relevant to $\mathrm{Cu}, \mathrm{Zn}$ superoxide dismutase," Journal of Biological Chemistry, vol. 279, no. 29, pp. 29938-29943, 2004.

[37] P. J. Lapinskas, K. W. Cunningham, X. F. Liu, G. R. Fink, and V. C. Culotta, "Mutations in PMR1 suppress oxidative damage in yeast cells lacking superoxide dismutase," Molecular and Cellular Biology, vol. 15, no. 3, pp. 1382-1388, 1995.

[38] S. Izawa, Y. Inoue, and A. Kimura, "Importance of catalase in the adaptive response to hydrogen peroxide: analysis of acatalasaemic Saccharomyces cerevisiae," Biochemical Journal, vol. 320, pp. 61-67, 1996.

[39] C. Schuller, J. L. Brewster, M. R. Alexander, M. C. Gustin, and H. Ruis, "The HOG pathway controls osmotic regulation of transcription via the stress response element (STRE) of the Saccharomyces cerevisiaeCTT1 gene," The EMBO Journal, vol. 13, no. 18, pp. 4382-4389, 1994.

[40] A. Mesquita, M. Weinberger, A. Silva et al., "Caloric restriction or catalase inactivation extends yeast chronological lifespan by inducing $\mathrm{H}_{2} \mathrm{O}_{2}$ and superoxide dismutase activity," Proceedings of the National Academy of Sciences of the United States of America, vol. 107, no. 34, pp. 15123-15128, 2010.

[41] M. Cap, L. Vachova, and Z. Palkova, "How to survive within a yeast colony? Change metabolism or cope with stress?" Communicative and Integrative Biology, vol. 3, pp. 198-200, 2010.

[42] B. G. Hill and and A. Bhatnagar, "Protein S-glutathiolation: redox-sensitive regulation of protein function," Journal of Molecular and Cellular Cardiology, vol. 52, pp. 559-567, 2012.

[43] A. C. Nulton-Persson and L. I. Szweda, "Modulation of mitochondrial function by hydrogen peroxide," Journal of Biological Chemistry, vol. 276, no. 26, pp. 23357-23361, 2001.

[44] M. D. Temple, G. G. Perrone, and I. W. Dawes, "Complex cellular responses to reactive oxygen species," Trends in Cell Biology, vol. 15, no. 6, pp. 319-326, 2005.

[45] Y. Pan, E. A. Schroeder, A. Ocampo, A. Barrientos, and G. S. Shadel, "Regulation of yeast chronological life span by TORC1 via adaptive mitochondrial ROS signaling," Cell Metabolism, vol. 13, no. 6, pp. 668-678, 2011.

[46] A. Karachitos, H. Galganska, M. Wojtkowska et al., "Cu,Znsuperoxide dismutase is necessary for proper function of VDAC in Saccharomyces cerevisiae cells," FEBS Letters, vol. 583, no. 2, pp. 449-455, 2009.

[47] J. J. Lemasters and E. Holmuhamedov, "Voltage-dependent anion channel (VDAC) as mitochondrial governatorthinking outside the box," Biochimica et Biophysica Acta, vol. 1762, no. 2, pp. 181-190, 2006.

[48] H. Galganska, M. Budzinska, M. Wojtkowska, and H. Kmita, "Redox regulation of protein expression in Saccharomyces cerevisiae mitochondria: possible role of VDAC," Archives of Biochemistry and Biophysics, vol. 479, no. 1, pp. 39-45, 2008.

[49] D. Han, F. Antunes, R. Canali, D. Rettori, and E. Cadenas, "Voltage-dependent anion channels control the release of the superoxide anion from mitochondria to cytosol," Journal of Biological Chemistry, vol. 278, no. 8, pp. 5557-5563, 2003.

[50] S. Sehati, M. H. S. Clement, J. Martins et al., "Metabolic alterations in yeast lacking copper-zinc superoxide dismutase," Free Radical Biology and Medicine, vol. 50, no. 11, pp. 15911598, 2011.

[51] D. Bonatto, "A systems biology analysis of protein-protein interactions between yeast superoxide dismutases and DNA repair pathways," Free Radical Biology and Medicine, vol. 43, no. 4, pp. 557-567, 2007.
[52] S. Büttner, T. Eisenberg, E. Herker, D. Carmona-Gutierrez, G. Kroemer, and F. Madeo, "Why yeast cells can undergo apoptosis: death in times of peace, love, and war," Journal of Cell Biology, vol. 175, no. 4, pp. 521-525, 2006.

[53] D. Carmona-Gutierrez, T. Eisenberg, S. Büttner, C. Meisinger, G. Kroemer, and F. Madeo, "Apoptosis in yeast: triggers, pathways, subroutines," Cell Death and Differentiation, vol. 17, no. 5, pp. 763-773, 2010.

[54] C. W. Gourlay, W. Du, and K. R. Ayscough, "Apoptosis in yeast-mechanisms and benefits to a unicellular organism," Molecular Microbiology, vol. 62, no. 6, pp. 1515-1521, 2006.

[55] F. Madeo, D. Carmona-Gutierrez, J. Ring, S. Büttner, T. Eisenberg, and G. Kroemer, "Caspase-dependent and caspase-independent cell death pathways in yeast," Biochemical and Biophysical Research Communications, vol. 382, no. 2, pp. 227-231, 2009.

[56] P. Fabrizio, L. Battistella, R. Vardavas et al., "Superoxide is a mediator of an altruistic aging program in Saccharomyces cerevisiae," Journal of Cell Biology, vol. 166, no. 7, pp. 10551067, 2004.

[57] K. M. Yeater, J. Chandra, G. Cheng et al., “Temporal analysis of Candida albicans gene expression during biofilm development," Microbiology, vol. 153, no. 8, pp. 2373-2385, 2007.

[58] C. J. Seneviratne, Y. Wang, L. Jin, Y. Abiko, and L. P. Samaranayake, "Candida albicans biofilm formation is associated with increased anti-oxidative capacities," Proteomics, vol. 8, no. 14, pp. 2936-2947, 2008.

[59] S. Younes, W. Bahnan, H. I. Dimassi, and R. A. Khalaf, “The Candida albicans Hwp2 is necessary for proper adhesion, biofilm formation and oxidative stress tolerance," Microbiological Research, vol. 166, no. 5, pp. 430-436, 2011.

[60] A. J. Brown, K. Haynes, and J. Quinn, "Nitrosative and oxidative stress responses in fungal pathogenicity," Current Opinion in Microbiology, vol. 12, no. 4, pp. 384-391, 2009.

[61] D. Vandenbosch, K. Braeckmans, H. J. Nelis, and T. Coenye, "Fungicidal activity of miconazole against Candida spp. biofilms," Journal of Antimicrobial Chemotherapy, vol. 65, no. 4, pp. 694-700, 2010.

[62] J. M. Hornby, E. C. Jensen, A. D. Lisec et al., "Quorum sensing in the dimorphic fungus Candida albicans is mediated by farnesol," Applied and Environmental Microbiology, vol. 67, no. 7, pp. 2982-2992, 2001.

[63] A. Davis-Hanna, A. E. Piispanen, L. I. Stateva, and D. A. Hogan, "Farnesol and dodecanol effects on the Candida albicans Ras1-cAMP signalling pathway and the regulation of morphogenesis," Molecular Microbiology, vol. 67, no. 1, pp. 47-62, 2008 .

[64] G. Ramage, S. P. Saville, B. L. Wickes, and J. L. LópezRibot, "Inhibition of Candida albicans biofilm formation by farnesol, a quorum-sensing molecule," Applied and Environmental Microbiology, vol. 68, no. 11, pp. 5459-5463, 2002.

[65] M. E. Shirtliff, B. P. Krom, R. A. M. Meijering et al., "Farnesol-induced apoptosis in Candida albicans," Antimicrobial Agents and Chemotherapy, vol. 53, no. 6, pp. 23922401, 2009.

[66] A. Deveau, A. E. Piispanen, A. A. Jackson, and D. A. Hogan, "Farnesol induces hydrogen peroxide resistance in Candida albicans yeast by inhibiting the Ras-cyclic AMP signaling pathway," Eukaryotic Cell, vol. 9, no. 4, pp. 569-577, 2010.

[67] C. Westwater, E. Balish, and D. A. Schofield, "Candida albicans-conditioned medium protects yeast cells from oxidative stress: a possible link between quorum sensing and oxidative 
stress resistance," Eukaryotic Cell, vol. 4, no. 10, pp. 1654 1661, 2005.

[68] D. J. Jamieson, D. W. S. Stephen, and E. C. Terrière, "Analysis of the adaptive oxidative stress response of Candida albicans," FEMS Microbiology Letters, vol. 138, no. 1, pp. 83-88, 1996.

[69] O. Nasution, K. Srinivasa, M. Kim et al., "Hydrogen peroxide induces hyphal differentiation in Candida albicans," Eukaryotic Cell, vol. 7, no. 11, pp. 2008-2011, 2008.

[70] H. Lu, Z. Zhu, L. Dong et al., "Lack of trehalose accelerates $\mathrm{H}_{2} \mathrm{O}_{2}$-induced Candida albicans apoptosis through regulating $\mathrm{Ca}^{2+}$ signaling pathway and caspase activity," PLoS ONE, vol. 6, no. 1, Article ID e15808, 2011.

[71] A. J. Phillips, I. Sudbery, and M. Ramsdale, "Apoptosis induced by environmental stresses and amphotericin B in Candida albicans," Proceedings of the National Academy of Sciences of the United States of America, vol. 100, no. 2, pp. 14327-14332, 2003.

[72] A. D. S. Dantas, M. J. Patterson, D. A. Smith et al., "Thioredoxin regulates multiple hydrogen peroxide-induced signaling pathways in Candida albicans," Molecular and Cellular Biology, vol. 30, no. 19, pp. 4550-4563, 2010.

[73] D. A. Smith, S. Nicholls, B. A. Morgan, A. J. P. Brown, and J. Quinn, "A conserved stress-activated protein kinase regulates a core stress response in the human pathogen Candida albicans," Molecular Biology of the Cell, vol. 15, no. 9, pp. 4179-4190, 2004.

[74] X. Zhang, M. De Micheli, S. T. Coleman, D. Sanglard, and W. S. Moye-Rowley, "Analysis of the oxidative stress regulation of the Candida albicans transcription factor, Cap1p," Molecular Microbiology, vol. 36, no. 3, pp. 618-629, 2000.

[75] C. Cugini, D. K. Morales, and D. A. Hogan, "Candida albicans-produced farnesol stimulates Pseudomonas quinolone signal production in LasR-defective Pseudomonas aeruginosa strains," Microbiology, vol. 156, no. 10, pp. 3096-3107, 2010.

[76] C. P. Semighini, J. M. Hornby, R. Dumitru, K. W. Nickerson, and S. D. Harris, "Farnesol-induced apoptosis in Aspergillus nidulans reveals a possible mechanism for antagonistic interactions between fungi," Molecular Microbiology, vol. 59, no. 3, pp. 753-764, 2006.

[77] K. Machida, T. Tanaka, K. I. Fujita, and M. Taniguchi, "Farnesol-induced generation of reactive oxygen species via indirect inhibition of the mitochondrial electron transport chain in the yeast Saccharomyces cerevisiae," Journal of Bacteriology, vol. 180, no. 17, pp. 4460-4465, 1998.

[78] M. J. Schmitt and F. Breinig, "Yeast viral killer toxins: lethality and self-protection," Nature Reviews, vol. 4, no. 3, pp. 212221, 2006.

[79] E. Karatan and P. Watnick, "Signals, regulatory networks, and materials that build and break bacterial biofilms," Microbiology and Molecular Biology Reviews, vol. 73, no. 2, pp. 310-347, 2009.

[80] J. H. Lee and J. Lee, "Indole as an intercellular signal in microbial communities," FEMS Microbiology Reviews, vol. 34, no. 4, pp. 426-444, 2010.

[81] W. L. Ng and B. L. Bassler, "Bacterial quorum-sensing network architectures," Annual Review of Genetics, vol. 43, pp. 197-222, 2009.

[82] B. W. Wortham, C. N. Patel, and M. A. Oliveira, "Polyamines in bacteria: pleiotropic effects yet specific mechanisms," Advances in Experimental Medicine and Biology, vol. 603, pp. 106-115, 2007.

[83] M. Allegrucci and K. Sauer, "Characterization of colony morphology variants isolated from Streptococcus pneumoniae biofilms," Journal of Bacteriology, vol. 189, no. 5, pp. 20302038, 2007.

[84] B. R. Boles, M. Thoendel, and P. K. Singh, "Self-generated diversity produces "insurance effects" in biofilm communities," Proceedings of the National Academy of Sciences of the United States of America, vol. 101, no. 47, pp. 16630-16635, 2004.

[85] E. Déziel, Y. Comeau, and R. Villemur, "Initiation of biofilm formation by Pseudomonas aeruginosa 57RP correlates with emergence of hyperpiliated and highly adherent phenotypic variants deficient in swimming, swarming, and twitching motilities," Journal of Bacteriology, vol. 183, no. 4, pp. 11951204, 2001.

[86] J. M. Yarwood, K. M. Paquette, U. B. Tikh, E. M. Volper, and E. P. Greenberg, "Generation of virulence factor variants in Staphylococcus aureus biofilms," Journal of Bacteriology, vol. 189, no. 22, pp. 7961-7967, 2007.

[87] S. van der Veen and T. Abee, "Generation of variants in Listeria monocytogenes continuous-flow biofilms is dependent on radical-induced DNA damage and RecA-mediated repair," PLoS ONE, vol. 6, Article ID e28590, 2011.

[88] G. Regev-Yochay, K. Trzcinski, C. M. Thompson, M. Lipsitch, and R. Malley, "SpxB is a suicide gene of Streptococcus pneumoniae and confers a selective advantage in an in vivo competitive colonization model," Journal of Bacteriology, vol. 189, no. 18, pp. 6532-6539, 2007.

[89] J. Kreth, H. Vu, Y. Zhang, and M. C. Herzberg, "Characterization of hydrogen peroxide-induced DNA release by Streptococcus sanguinis and Streptococcus gordonii," Journal of Bacteriology, vol. 191, no. 20, pp. 6281-6291, 2009.

[90] A. Itzek, L. Zheng, Z. Chen, J. Merritt, and J. Kreth, "Hydrogen peroxide-dependent DNA release and transfer of antibiotic resistance genes in Streptococcus gordonii," Journal of Bacteriology, vol. 193, pp. 6912-6922, 2011.

[91] M. Harmsen, M. Lappann, S. Knøchel, and S. Molin, "Role of extracellular DNA during biofilm formation by listeria monocytogenes," Applied and Environmental Microbiology, vol. 76, no. 7, pp. 2271-2279, 2010.

[92] M. Lappann, H. Claus, T. van Alen et al., "A dual role of extracellular DNA during biofilm formation of Neisseria meningitidis," Molecular Microbiology, vol. 75, no. 6, pp. 1355-1371, 2010.

[93] K. C. Rice, E. E. Mann, J. L. Endres et al., "The cidA murein hydrolase regulator contributes to DNA release and biofilm development in Staphylococcus aureus," Proceedings of the National Academy of Sciences of the United States of America, vol. 104, no. 19, pp. 8113-8118, 2007.

[94] V. C. Thomas, Y. Hiromasa, N. Harms, L. Thurlow, J. Tomich, and L. E. Hancock, "A fratricidal mechanism is responsible for eDNA release and contributes to biofilm development of Enterococcus faecalis," Molecular Microbiology, vol. 72, no. 4, pp. 1022-1036, 2009.

[95] C. B. Whitchurch, T. Tolker-Nielsen, P. C. Ragas, and J. S. Mattick, "Extracellular DNA required for bacterial biofilm formation," Science, vol. 295, no. 5559, Article ID 1487, 2002.

[96] Y. H. Li, P. C. Y. Lau, J. H. Lee, R. P. Ellen, and D. G. Cvitkovitch, "Natural genetic transformation of streptococcus mutans growing in biofilms," Journal of Bacteriology, vol. 183, no. 3, pp. 897-908, 2001.

[97] E. S. Henle and S. Linn, "Formation, prevention, and repair of DNA damage by iron/hydrogen peroxide," Journal of Biological Chemistry, vol. 272, no. 31, pp. 19095-19098, 1997.

[98] L. Zheng, Z. Chen, A. Itzek, M. Ashby, and J. Kreth, "Catabolite control protein a controls hydrogen peroxide 
production and cell death in streptococcus sanguinis," Journal of Bacteriology, vol. 193, no. 2, pp. 516-526, 2011.

[99] A. Mai-Prochnow, P. Lucas-Elio, S. Egan et al., "Hydrogen peroxide linked to lysine oxidase activity facilitates biofilm differentiation and dispersal in several gram-negative bacteria," Journal of Bacteriology, vol. 190, no. 15, pp. 5493-5501, 2008.

[100] A. Mai-Prochnow, J. S. Webb, B. C. Ferrari, and S. Kjelleberg, "Ecological advantages of autolysis during the development and dispersal of Pseudoalteromonas tunicata biofilms," Applied and Environmental Microbiology, vol. 72, no. 8, pp. 5414-5420, 2006.

[101] N. Barraud, D. J. Hassett, S. H. Hwang, S. A. Rice, S. Kjelleberg, and J. S. Webb, "Involvement of nitric oxide in biofilm dispersal of Pseudomonas aeruginosa," Journal of Bacteriology, vol. 188, no. 21, pp. 7344-7353, 2006.

[102] G. Borriello, E. Werner, F. Roe, A. M. Kim, G. D. Ehrlich, and P. S. Stewart, "Oxygen limitation contributes to antibiotic tolerance of Pseudomonas aeruginosa in biofilms," Antimicrobial Agents and Chemotherapy, vol. 48, no. 7, pp. 2659-2664, 2004.

[103] E. Werner, F. Roe, A. Bugnicourt et al., "Stratified growth in Pseudomonas aeruginosa biofilms," Applied and Environmental Microbiology, vol. 70, no. 10, pp. 6188-6196, 2004.

[104] P. Kovacic, "Unifying mechanism for bacterial cell signalers (4,5-dihydroxy-2,3-pentanedione, lactones and oligopeptides): electron transfer and reactive oxygen species. Practical medical features," Medical Hypotheses, vol. 69, no. 5, pp. 1105-1110, 2007.

[105] T. Abee, A. T. Kovacs, O. P. Kuipers, and S. van der Veen, "Biofilm formation and dispersal in Gram-positive bacteria," Current Opinion in Biotechnology, vol. 22, no. 2, pp. 172-179, 2011.

[106] J. M. Rothfork, G. S. Timmins, M. N. Harris et al., "Inactivation of a bacterial virulence pheromone by phagocytederived oxidants: new role for the NADPH oxidase in host defense," Proceedings of the National Academy of Sciences of the United States of America, vol. 101, no. 38, pp. 1386713872, 2004

[107] T. Ohsawa, K. Tsukahara, T. Sato, and M. Ogura, "Superoxide stress decreases expression of srfA through inhibition of transcription of the comQXP quorum-sensing locus in Bacillus subtilis," Journal of Biochemistry, vol. 139, no. 2, pp. 203-211, 2006.

[108] R. L. Frey, L. He, Y. Cui et al., "Reaction of N-acylhomoserine lactones with hydroxyl radicals: rates, products, and effects on signaling activity," Environmental Science and Technology, vol. 44, no. 19, pp. 7465-7469, 2010.

[109] D. J. Hassett, J. F. Ma, J. G. Elkins et al., "Quorum sensing in Pseudomonas aeruginosa controls expression of catalase and superoxide dismutase genes and mediates biofilm susceptibility to hydrogen peroxide," Molecular Microbiology, vol. 34, no. 5, pp. 1082-1093, 1999.

[110] A. Joelsson, B. Kan, and J. Zhu, "Quorum sensing enhances the stress response in Vibrio cholerae," Applied and Environmental Microbiology, vol. 73, no. 11, pp. 3742-3746, 2007.

[111] M. H. Pontes, M. Babst, R. Lochhead, K. Oakeson, K. Smith, and C. Dale, "Quorum sensing primes the oxidative stress response in the insect endosymbiont, Sodalis glossinidius," PLoS ONE, vol. 3, no. 10, Article ID e3541, 2008.

[112] S. Uzureau, J. Lemaire, E. Delaive et al., "Global analysis of quorum sensing targets in the intracellular pathogen Brucella melitensis 16 M," Journal of Proteome Research, vol. 9, no. 6, pp. 3200-3217, 2010.
[113] M. Srivastava, C. Mallard, T. Barke, L. E. Hancock, and W. T. Self, "A selenium-dependent xanthine dehydrogenase triggers biofilm proliferation in Enterococcus faecalis through oxidant production," Journal of Bacteriology, vol. 193, no. 7, pp. 1643-1652, 2011.

[114] M. M. Ramsey and M. Whiteley, "Polymicrobial interactions stimulate resistance to host innate immunity through metabolite perception," Proceedings of the National Academy of Sciences of the United States of America, vol. 106, no. 5, pp. 1578-1583, 2009.

[115] J. Domka, J. Lee, and T. K. Wood, "YliH (BssR) and YceP (BssS) regulate Escherichia coli K-12 biofilm formation by influencing cell signaling," Applied and Environmental Microbiology, vol. 72, no. 4, pp. 2449-2459, 2006.

[116] J. Lee, A. Jayaraman, and T. K. Wood, "Indole is an interspecies biofilm signal mediated by SdiA," BMC Microbiology, vol. 7, article no. 42, 2007.

[117] D. Ren, L. A. Bedzyk, S. M. Thomas, R. W. Ye, and T. K. Wood, "Gene expression in Escherichia coli biofilms," Applied Microbiology and Biotechnology, vol. 64, no. 4, pp. 515-524, 2004.

[118] M. Zheng, X. Wang, L. J. Templeton, D. R. Smulski, R. A. LaRossa, and G. Storz, "DNA microarray-mediated transcriptional profiling of the Escherichia coli response to hydrogen peroxide," Journal of Bacteriology, vol. 183, no. 15, pp. 4562-4570, 2001.

[119] T. R. Garbe, M. Kobayashi, and H. Yukawa, "Indole-inducible proteins in bacteria suggest membrane and oxidant toxicity," Archives of Microbiology, vol. 173, no. 1, pp. 78-82, 2000.

[120] D. Kuczyńska-Wiśnik, E. Matuszewska, B. Furmanek-Blaszk et al., "Antibiotics promoting oxidative stress inhibit formation of Escherichia coli biofilm via indole signalling," Research in Microbiology, vol. 161, no. 10, pp. 847-853, 2010.

[121] P. Di Martino, R. Fursy, L. Bret, B. Sundararaju, and R. S. Phillips, "Indole can act as an extracellular signal to regulate biofilm formation of Escherichia coli and other indoleproducing bacteria," Canadian Journal of Microbiology, vol. 49, no. 7, pp. 443-449, 2003.

[122] J. P. Bitoun, A. H. Nguyen, Y. Fan, R. A. Burne, and Z. T. Wen, "Transcriptional repressor Rex is involved in regulation of oxidative stress response and biofilm formation by Streptococcus mutans," FEMS Microbiology Letters, vol. 320, no. 2, pp. 110-117, 2011.

[123] Z. T. Wen, P. Suntharaligham, D. G. Cvitkovitch, and R. A. Burne, "Trigger factor in Streptococcus mutans is involved in stress tolerance, competence development, and biofilm formation," Infection and Immunity, vol. 73, no. 1, pp. 219225, 2005.

[124] A. P. Hodges, D. Dai, Z. Xiang, P. Woolf, C. Xi, and Y. He, "Bayesian network expansion identifies new ROS and biofilm regulators,” PLoS ONE, vol. 5, no. 3, Article ID e9513, 2010.

[125] J. A. Fields and S. A. Thompson, "Campylobacter jejuni CsrA mediates oxidative stress responses, biofilm formation, and host cell invasion," Journal of Bacteriology, vol. 190, no. 9, pp. 3411-3416, 2008.

[126] Q. Yan and N. Wang, "The ColR/ColS two-component system plays multiple roles in the pathogenicity of the citrus canker pathogen Xanthomonas citri subsp. citri," Journal of Bacteriology, vol. 193, no. 7, pp. 1590-1599, 2011.

[127] K. S. Choi, Y. Veeraragouda, K. Cho et al., "Effect of gacS and gacA mutations on colony architecture, surface motility, biofilm formation and chemical toxicity in Pseudomonas sp. KL28," Journal of Microbiology, vol. 45, no. 6, pp. 492-498, 2007. 
[128] M. S. B. Paget and M. J. Buttner, "Thiol-based regulatory switches," Annual Review of Genetics, vol. 37, pp. 91-121, 2003.

[129] P. N. Danese, L. A. Pratt, S. L. Dove, and R. Kolter, "The outer membrane protein, antigen 43, mediates cell-tocell interactions within Escherichia coli biofilms," Molecular Microbiology, vol. 37, no. 2, pp. 424-432, 2000.

[130] C. Hennequin and C. Forestier, " $O x y R$, a LysR-type regulator involved in Klebsiella pneumoniae mucosal and abiotic colonization," Infection and Immunity, vol. 77, no. 12, pp. 5449-5457, 2009.

[131] R. M. Q. Shanks, N. A. Stella, E. J. Kalivoda et al., "A Serratia marcescens OxyR homolog mediates surface attachment and biofilm formation," Journal of Bacteriology, vol. 189, no. 20, pp. 7262-7272, 2007.

[132] K. Honma, E. Mishima, S. Inagaki, and A. Sharma, "The OxyR homologue in Tannerella forsythia regulates expression of oxidative stress responses and biofilm formation," Microbiology, vol. 155, no. 6, pp. 1912-1922, 2009.

[133] K. L. Seib, H. J. Wu, Y. N. Srikhanta et al., "Characterization of the OxyR regulon of Neisseria gonorrhoeae," Molecular Microbiology, vol. 63, no. 1, pp. 54-68, 2007.

[134] I. Albesa, M. C. Becerra, P. C. Battán, and P. L. Páez, "Oxidative stress involved in the antibacterial action of different antibiotics," Biochemical and Biophysical Research Communications, vol. 317, no. 2, pp. 605-609, 2004.

[135] D. J. Dwyer, M. A. Kohanski, and J. J. Collins, "Role of reactive oxygen species in antibiotic action and resistance," Current Opinion in Microbiology, vol. 12, no. 5, pp. 482-489, 2009.

[136] M. A. Kohanski, D. J. Dwyer, B. Hayete, C. A. Lawrence, and J. J. Collins, "A common mechanism of cellular death induced by bactericidal antibiotics," Cell, vol. 130, no. 5, pp. 797-810, 2007. 


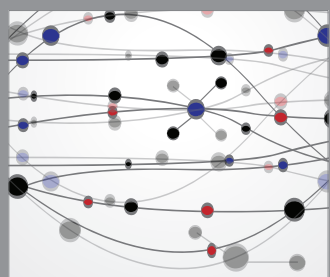

The Scientific World Journal
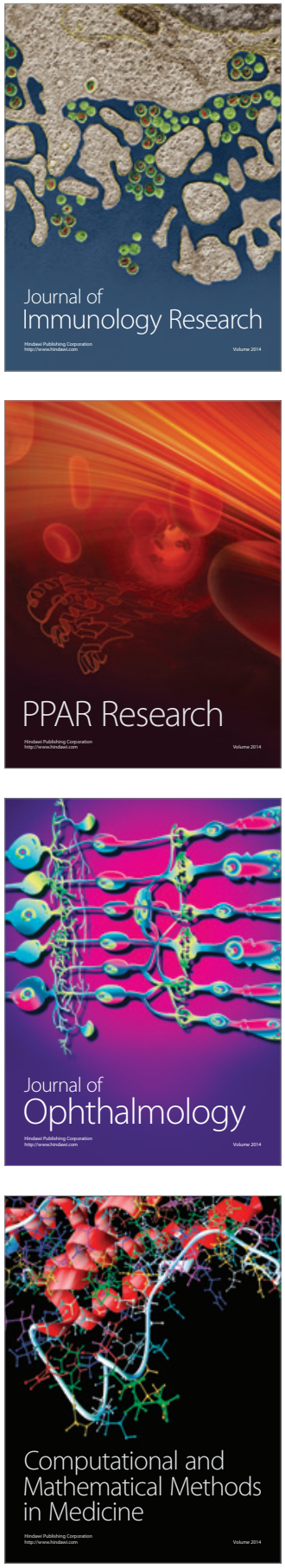

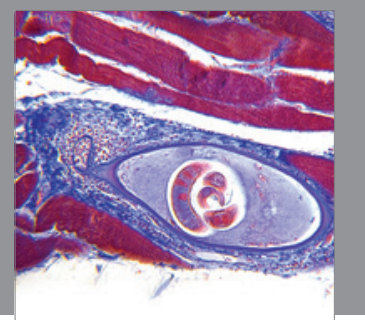

Gastroenterology

Research and Practice
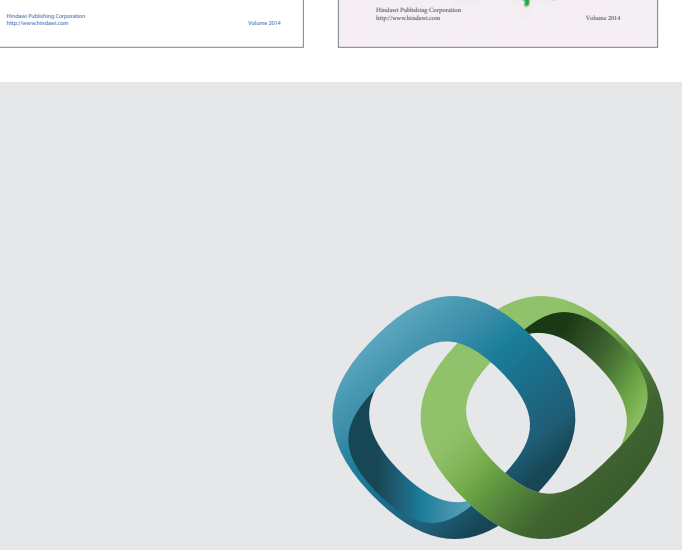

\section{Hindawi}

Submit your manuscripts at

http://www.hindawi.com
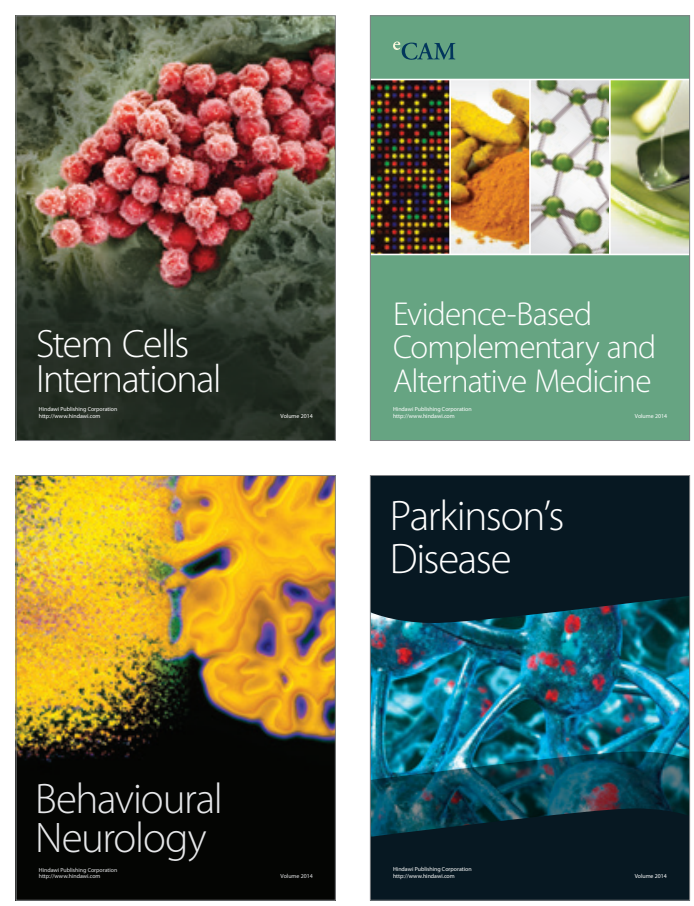

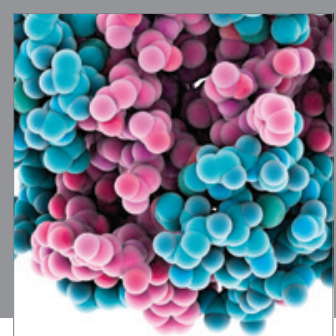

Journal of
Diabetes Research

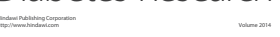

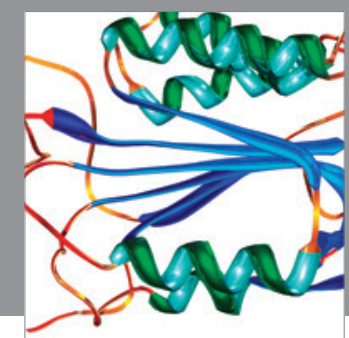

Disease Markers
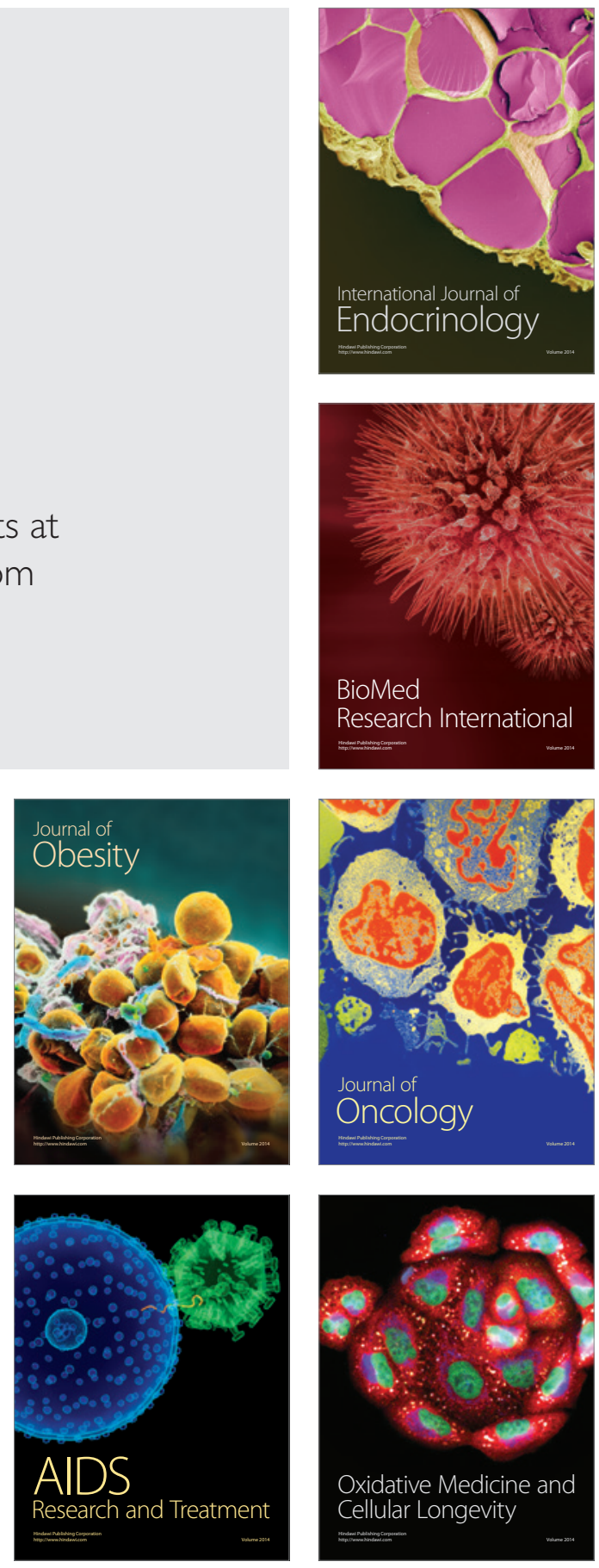